Document downloaded from:

http://hdl.handle.net/10251/98643

This paper must be cited as:

Allvarez, C.; Alcázar-Ortega, M.; Escrivá-Escrivá, G.; ANTONIO GABALDON MARIN (2009). Technical and economical tools to assess customer demand response in the commercial sector. Energy Conversion and Management. 50(10):2605-2612. doi:10.1016/j.enconman.2009.06.002

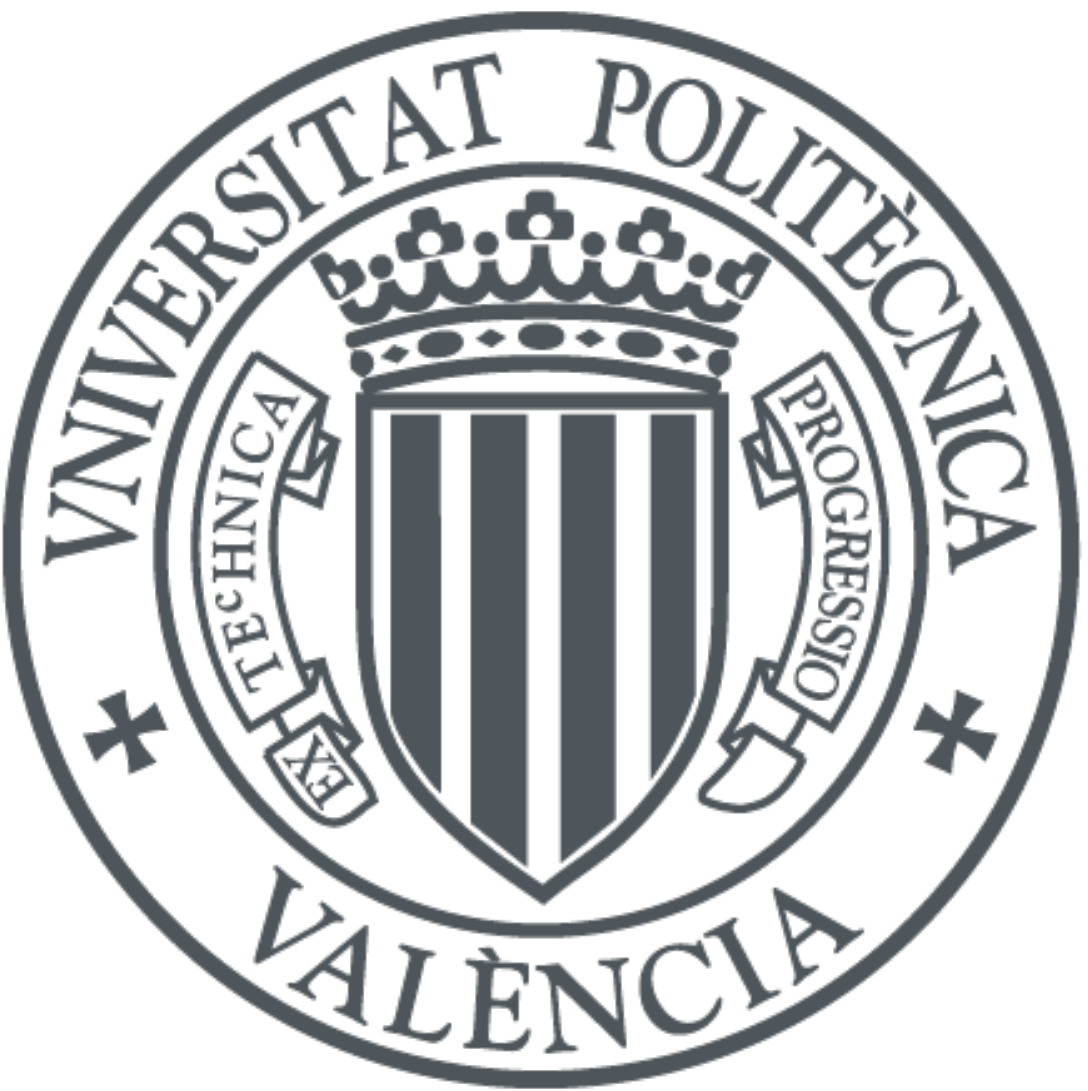

The final publication is available at

https://doi.org/10.1016/j.enconman.2009.06.002

Copyright Elsevier

Additional Information 


\title{
TECHNICAL AND ECONOMICAL TOOLS TO ASSESS CUSTOMER DEMAND RESPONSE IN THE COMMERCIAL SECTOR
}

\author{
Carlos Álvarez Bel( $\left({ }^{\star}\right)\left({ }^{a}\right)$, Manuel Alcázar Ortega $\left({ }^{(}\right)$, Guillermo Escrivá Escrivá( $\left.{ }^{a}\right)$, Antonio \\ Gabaldón Marín $\left({ }^{\mathrm{b}}\right)$
}

(a) Institute for Energy Engineering, Universidad Politécnica de Valencia, Camino de Vera, s/n, edificio 8E, escalera F, 5 a planta. 46022 Valencia (SPAIN) (e-mail: calvarez@die.upv.es)

$\left({ }^{b}\right)$ Department of Electrical Engineering, Universidad Politécnica de Cartagena, Campus de la Muralla al Mar. 30202 Cartagena (SPAIN) (e-mail: antonio.gabaldon@upct.es)

\begin{abstract}
The authors present a methodology to evaluate and quantify the economic parameters (costs and benefits) attached to customer electricity consumption by analyzing the service provided by the different "pieces" of absorbed electricity. The first step of this methodology is to perform a process oriented market segmentation to identify segments according to their flexibility potential. After that, a procedure based on comprehensive simulations to identify and quantify the actual demand that can be managed in the short term is presented and, finally, the required economic analysis is performed. The methodology, which is demonstrated with some applications to the commercial sector, not only helps the customers to integrate in flexible distribution systems but also offers the necessary economical parameters for them to integrate in electricity markets.
\end{abstract}

\footnotetext{
* Corresponding Author: Carlos Álvarez Bel. Institute for Energy Engineering. Universidad Politécnica de Valencia. Camino de Vera, s/n, edificio 8E, escalera F, $5^{\mathrm{a}}$ planta. 46022 Valencia (SPAIN). Telf. +34 963879240 Fax: +34 963877272 email: calvarez@die.upv.es
} 
Keywords: Deregulated power markets; Distributed energy resources; Demand response resources; Demand modelling; Responsive demand participation

\section{Introduction}

The use of the flexibility in energy consumption by the customers is basic for the effective integration of other Distributed Energy Resources. To achieve this Demand Response capability, the customers must identify what they are using the energy for and assign prices to both the benefits they obtain by consuming electricity and the costs they may incur by giving up some of the electricity consumption in the short term. Significant research has been recently implemented worldwide to identify the Demand Response Resources in the electricity market.

Competition has acquired a major role in electricity industry due to power markets restructuring. A desired market performance requires the demand to be flexible [1] in the sense that the electricity consumption changes according to electricity prices. Active Demand-Side participation can decrease supply side agents' market power and help these markets to achieve a better operation [2] [3]. In order to maintain market efficiency, demand response should be considered as a service that consumers give to the grid, and consequently, it should be financed through market mechanisms and not through subsides. In this sense, electricity customers should be prepared to take advantage of its flexibility for the energy and power trading either in open markets (wholesale, retail, balancing, etc.) or by forcing the energy supplier to trade tailored bilateral contracts that account for this flexibility. They may also use their flexibility to participate in either regulated or deregulated demand response programs as those being developed around the world [4] [5] and where the consumers do not participate directly in the market but interact with an aggregator or other agents.

Up to now, demand participation in electricity markets has not occurred spontaneously and new tools are required for encourage it. This paper proposes a methodology to ease the identification and assessment of demand response resources with market participation purposes.

Large electricity customers and energy traders may participate by buying energy through demand bids in forward markets (Day Ahead and/or Intra-Day). After this energy transaction is somehow firm, they may participate in shorter term markets just as generators do, selling some 
of the energy previously bought by offering reductions in Balancing or other Ancillary Services markets. It is important to reinforce that, for selling energy reductions it is required that the energy has been previously bought in other markets. If not, the customers would be selling energy that they do not own [6]. For practical reasons small and residential consumers are usually not allowed to participate directly in markets, but could participate by managed aggregators in a similar way.

It is necessary that customers willing to exploit their flexibility in the energy consumption have to identify their Demand Response potential by organizing their demand according to the flexibility of their loads and identify the prices they are willing to pay for consuming electricity or to be paid for reducing those loads. Therefore, the evaluation of the customer Demand Response potential requires the evaluation of two components: technical and economical potential.

In order to evaluate these potentials, new tools are required and, due to the different energy consuming processes existent in different types of customers, they would depend on the specific type of customer the tools are dedicated to. Commercial customers are intense electricity consumers worldwide, and the processes where the energy is used in this sector are quite reduced in comparison to the industrial customers, where almost every industrial process requires a singular analysis. The main processes in this sector are Heat, Ventilation and Air Conditioning (HVAC), illumination and electronic equipment.

Evaluation tools for these two purposes are presented and discussed in this paper. These tools have been partially developed in the framework of a 6FP of the European Commission, EU-DEEP (research project funded by the European Commission with the objective identify and overcome barriers that prevent the utilization of Distributed Energy and Demand Response Resources) and developed for customer segments that have been previously identified as highly potential in Demand Response, both in the commercial and industrial sectors [7]

This paper is organized as follows: the first section is devoted to analyze the commercial sector in order to identify where the potential for DR is. The organization of the demand of the commercial customers in order to evaluate the amount of available flexibility (technical flexibility) is dealt with in section 3 , based on an improvement of a methodology previously proposed by the authors. 
The economical issues associated to the DR are discussed in section 4. One detailed application example is described and analyzed in section 5 and, finally, some conclusions are drawn in section 6 .

\section{Technical Demand Response Potential in the Commercial Sector}

The commercial sector has been analyzed in detail in the work performed in the above mentioned EU-DEEP project, where utilities covering more than 80 million customers all over Europe have been involved. The first step in this project was to perform a segmentation of the commercial sector based on the way in which the energy was used in the different segments [8].

These segments where afterwards ranked according to the potential to implement different Distributed Energy Resources implementations, such as distributed generation (DG), distributed storage (DS) or Demand Response (DR). The commercial segments in the top of the DR ranking top segments where: Universities and schools, hospitals, malls, hotels and offices.

After the most promising segments were identified, a detailed modelling of the main energy consuming processes was performed based on the physical description of the typical customer for the segment, and also accounting for the expected dispersion in the parameters and equipment describing this facility.

Most of the customers in the same segment have similar final uses of energy in the same processes, what allows considering similar reaction to energy prices. The share of the more relevant energy consuming processes for the most DR potential segments is shown in table 1. 
Table 1.

Process energy contribution to the consumed energy by the customers (source EU-DEEP)

\begin{tabular}{|c|c|c|c|c|c|c|c|c|}
\hline $\begin{array}{l}\text { Segment } \\
\text { description }\end{array}$ & $\begin{array}{l}\text { Climatic } \\
\text { zone }\end{array}$ & $\begin{array}{l}\text { Heating } \\
\text { Space }\end{array}$ & $\begin{array}{l}\text { Cooling } \\
\text { Space }\end{array}$ & $\begin{array}{l}\text { Heating } \\
\text { Hot } \\
\text { Water }\end{array}$ & Ventilation & Lighting & Electronics & Others \\
\hline $\begin{array}{l}\text { Universities } \\
\text { with sport } \\
\text { facilities }\end{array}$ & $\begin{array}{l}\text { Southern } \\
\text { Europe }\end{array}$ & $17 \%$ & $21 \%$ & $15 \%$ & $6 \%$ & $21 \%$ & $13 \%$ & $7 \%$ \\
\hline $\begin{array}{l}\text { Small } \\
\text { Hospitals }\end{array}$ & $\begin{array}{l}\text { Northern } \\
\text { Europe }\end{array}$ & $46 \%$ & $6 \%$ & $19 \%$ & $6 \%$ & $15 \%$ & $1 \%$ & $7 \%$ \\
\hline $\begin{array}{l}\text { Shopping } \\
\text { malls }\end{array}$ & $\begin{array}{l}\text { Southern } \\
\text { Europe }\end{array}$ & $16 \%$ & $30 \%$ & $5 \%$ & $10 \%$ & $15 \%$ & $2 \%$ & $22 \%$ \\
\hline $\begin{array}{l}\text { Standard } \\
\text { Hotels }\end{array}$ & $\begin{array}{l}\text { Southern } \\
\text { Europe }\end{array}$ & $12 \%$ & $30 \%$ & $10 \%$ & $15 \%$ & $10 \%$ & $1 \%$ & $22 \%$ \\
\hline $\begin{array}{l}\text { Large } \\
\text { Offices }\end{array}$ & $\begin{array}{l}\text { Northern } \\
\text { Europe }\end{array}$ & $34 \%$ & $14 \%$ & $5 \%$ & $10 \%$ & $18 \%$ & $6 \%$ & $13 \%$ \\
\hline $\begin{array}{l}\text { Large } \\
\text { Offices }\end{array}$ & $\begin{array}{l}\text { Southern } \\
\text { Europe }\end{array}$ & $22 \%$ & $30 \%$ & $5 \%$ & $10 \%$ & $15 \%$ & $8 \%$ & $10 \%$ \\
\hline Restaurants & $\begin{array}{l}\text { Northern } \\
\text { Europe }\end{array}$ & $35 \%$ & $20 \%$ & $16 \%$ & $5 \%$ & $10 \%$ & $1 \%$ & $13 \%$ \\
\hline $\begin{array}{l}\text { Small } \\
\text { Shops }\end{array}$ & $\begin{array}{l}\text { Southern } \\
\text { Europe }\end{array}$ & $15 \%$ & $20 \%$ & $5 \%$ & $5 \%$ & $25 \%$ & $0 \%$ & $30 \%$ \\
\hline $\begin{array}{l}\text { Small } \\
\text { Offices }\end{array}$ & $\begin{array}{l}\text { Southern } \\
\text { Europe }\end{array}$ & $25 \%$ & $32 \%$ & $4 \%$ & $6 \%$ & $15 \%$ & $8 \%$ & $10 \%$ \\
\hline
\end{tabular}

Demand Response requires the customer demand to be organized according to the specific uses or processes where the electricity is consumed. Therefore, the identification of the flexibility in the energy consumption has necessarily associated to a detailed analysis, based on physical and economical concepts, of the processes in each customer facility.

The potentials of these top DR customers have been estimated by using tools developed in the project of the International Energy Agency IEA task XIII, Demand Response Resources [9], of the Implementing Agreement on Demand Side Management. These tools estimate the available market potential for demand response in electricity markets. For the calculation, benchmark information gathered from experiences with consumers in Europe and America is used. Flexibility strategies for residential and small commercial customers are associated to direct load control programs for air conditioners, water heaters and space heating systems by using the North American long-term program participation rates. Table 2 shows the inputs considered in order to estimate the potential of demand response in hotels (EU25), which has been evaluated in $3180 \mathrm{MW}$. 
Table 2.

Inputs for the IEA Task XIII tool

Number of hotels in Europe

Peak power in EU25, MW

Peak power for a typical hotel, MW

Avg reducible power for a typical hotel, MW

Estimated potential in hotels (EU25), MW
132.400 485.299

0,272

0,149 3180
Source: The European Hotel Industry

Source: REE, NG, RTE, Eurostat

Source: UPV Models

Source: UPV Models

Task XIII tool

According to these results, it is possible to conclude that commercial sector has a high potential to provide demand response resources being several the barriers that prevent its realisation, as the lack of enabling technologies to perform DS response, legislative market barriers or the need of evaluation tools. The lack of knowledge the customer has about the impact (cost plus drawbacks) that he has from implementing DR actions and, consequently, the impossibility he has to value it with the incentives he may receive after the DR action is settled.

The evaluation of the impact the customer has from using DR resources is directly related to the "piece" of energy use that is going to be modified (usually partially or totally interrupted): air conditioning, space heating lighting, etc. Therefore, in order to assess about this impact, it is required to analyze, for each end use, the relation between the service provided (heat, cold, illumination, etc.) and the electricity that is being absorbed by the process so that the cost associated to the implementation of the DR and the degradation of the process can be evaluated. The models that have to be used for that purpose are "physical" where all the variables related have to be included and related with the physical laws driving the process. The use of this modelling methodology to customer demand organization was presented in [10], where the suitability of the methodology was demonstrated by the application to one customer.

This methodology stated in [10] has been extensively used in EU-DEEP project to evaluate both the technical and economical potential of the customer flexibility to assess the flexibility capability of customers in the commercial, industrial and residential sectors. The aggregated flexibility potential of selected customers is going to be validated through three real life market experiments, being the first one going to be implemented in the UK, where the use of DR to balance renewable wind electricity production and other balancing services is to be investigated.

This first experiment has been encouraged by the possibilities that BETTA market structure offers to the utilization of Demand Response Resources. The potential has been estimated in 
previous studies and results, as the one shown in Figure 1, have been produced for any specific commercial customer in the studied portfolio.
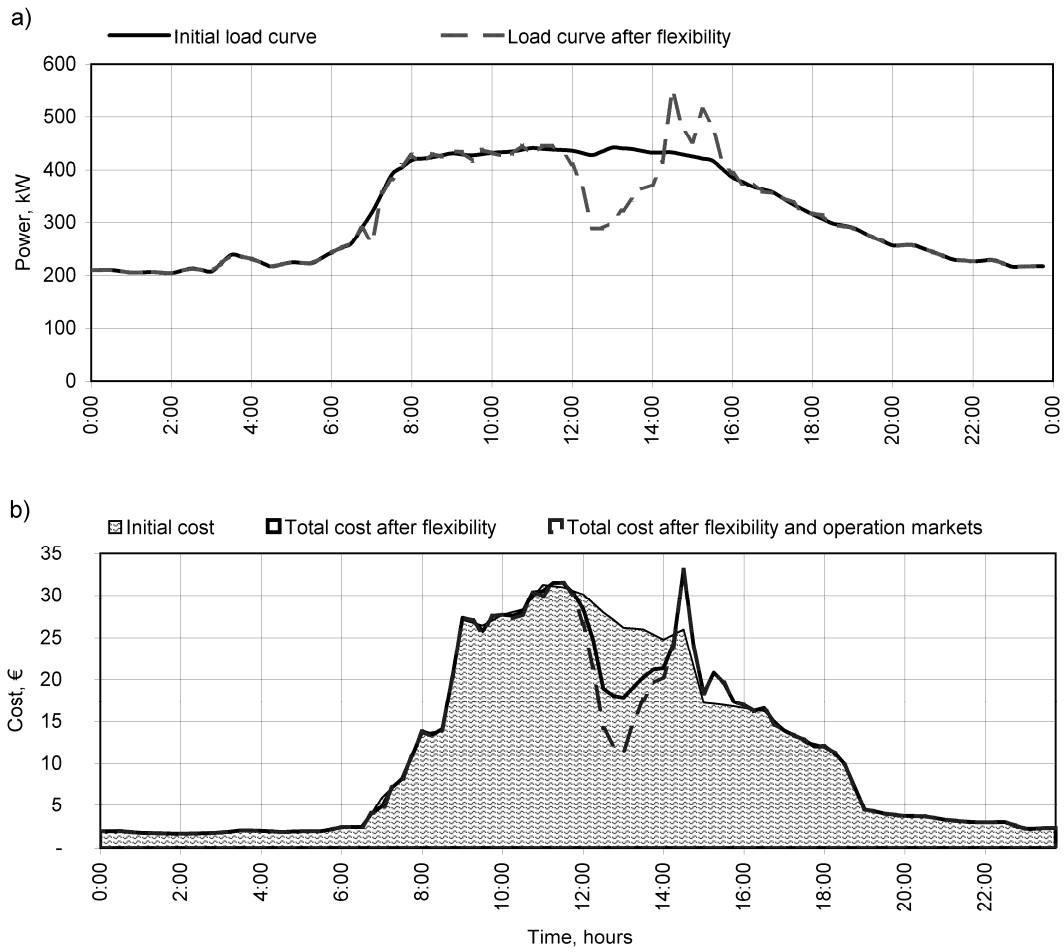

Figure 1. Expected savings, based on the DRR technical potential, of a "large offices" customer segment.

The demand for this customer for a typical summer day is shown in Figure $1 \mathrm{a}$ ), as well as its associated cost is shown in Figure $1 \mathrm{~b}$ ), without implementing DRR (continuous line) and with the implementation of Demand Response (discontinuous line). The flexibility in this case corresponds to direct air conditioning cycling and ventilation reduction. The benefit evaluation of the DR comes from two components: the reduction of the energy cost according to the actual supply contract (hourly prices have been considered in this example) and the ones resulting from the participation in the balancing mechanisms. In the example shown in Figure 1, reductions of $3 \%$ are obtained in the total electricity bill if only saves due to consuming electricity when prices are cheaper are considered. When it is considered the participation in other markets (i.e. balancing markets), additional profits are obtained (as shown in the figure), and saves may increase up to $7 \%$. 


\section{Technical Evaluation of the Flexibility}

The technical potential of this customer is evaluated by splitting the demand according to the final use: Air Conditioning, ventilation, electronic equipment, water heating, lighting (indoor and outdoor) and other. The idea behind the proposed methodology is to identify energy pieces or packages (EP) associated to some consumption where the flexibility is suspected. It means that these EPs can be interrupted if economically profitable.

The procedure to specify the different energy packages was already proposed by the authors [10], and it can be summarized according to the following steps:

1. According to the predicted activity for the customer in the short term (from one day to one week typically) determine the amount of flexible loads for each hour of the next day. A typical result for this step can be found in Figure 2 where by performing the required simulations, the amount of flexible power for each end use is determined for a large office customer. This curve is built by carrying out simulations for the different hours during a typical day, which allows investigating the amount of power to be reduced according to the selected scenario premises. Most of the premises include different flexibility options that have been identified by the consumers in surveys, so deviations beyond acceptable levels (for temperature, illumination level or humidity, etc) are not allowed. It is easy to generate, from this curve, short term offers (hourly or 15 minutes) for demand reduction.

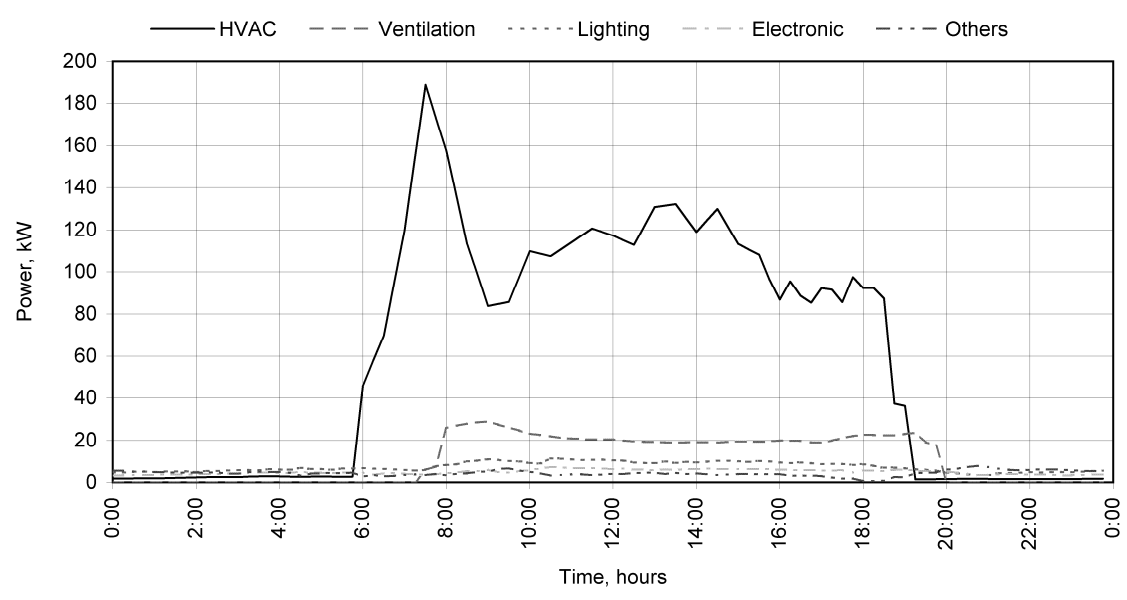

Figure 2. Flexibility curve divided into processes, of a "large offices" customer segment. 
2. Determine, using suitable demand models and simulations for every hour, the number of EPs that can be offered in every hour of the next day for any end use in the customer facility. It is necessary in order to evaluate this, to have accurate models to evaluate the impact in the customer of any possible flexibility action such as interruption, load cycling or any other control. As an example of the implementation of this step, it was identified for a Hotel customer that $125 \mathrm{~kW}$ are used for air conditioning a summer day from 14 to 16 hours. After performing simulations that account for the customer characteristics, it is obtained that an average of $85 \mathrm{~kW}$ can be reduced, for two hours, from this process just by controlling (cycling) the AC units, not having a degradation of the internal temperature higher than $2{ }^{\circ} \mathrm{C}$ (above the thermostat set point). Different amount of power could be released at this hour if more temperature degradation is allowed or if shorter time for the implementation of the flexibility action is considered. Consequently, these packages would have different sizes depending on the harshness of the control option: the higher is the reduction in temperature and the shorter the control is, the more power may be offered.

3. Each piece of flexible energy has an associated cost when implemented, that is when the flexibility is used, and therefore, the next step is to put a price to any EP. The methodology to perform this step is detailed in the next section. The price for each EP is based on the extra cost derived both in the short-term impact of the expected loss of service (comfort) and the cost of the equipment to implement the required control, as it is explained later. Several packages for each end use could be found, with different prices according to the severity of the control: the more power is offered, the highest the impact of the loss of control and, then, the associated price are.

Summarizing, the objective of the proposed methodology is to obtain, for every end use in the customer, tall possible flexible energy packages and their price. Once these components, size and prize, are identified for each EP, the flexibility is completely described and can be used for 
trading. The flexibility results discussed have to be completed with an economic analysis in order to account for the costs motivated by the use of the customer flexibility. These costs and the way to organize the whole process are discussed in the next section.

\section{Economical Evaluation}

The use of the customer flexibility has two cost components: Direct and Indirect costs.

The direct costs are related to the costs that have to be incurred in order to have the technical possibility to perform the flexibility action. This cost is specific for every flexibility action and the typical costs that have to be considered here are:

- Equipment for monitoring and control the flexible processes. This equipment is probably used for other applications apart to implement flexibility options and therefore, the cost has to be shared among the involved applications.

- Energy Storage, cost that will depend very much of the form in which the energy is stored (electricity, heat or cold). The use of the energy storage has to be discriminated, in order to assign the proper cost, into previously programmed (regular) use and use for Price Response.

- Stand-by generation, in case the flexibility action involves alternative supply

The indirect costs refer to the costs associated to the reduction in the quality of the service because of the implementation of a flexibility action: costs associated to the loss of comfort (temperature degradation), loss of productivity, etc. These indirect costs are usually difficult to identify and, because of that, no service degradation has been traditionally allowed in customers of the commercial sector. Nevertheless, as the price of the energy, and particularly the electricity, is increasing in continuously basis worldwide, the evaluation of these indirect costs will be performed by most customers in the commercial sector. These indirect costs are basically associated to extra labour costs and loss of revenues.

For example, the cost associated to a flexibility action consisting in switching some loads to the stand by generation will have to consider only direct costs, as the load is not going to be reduced, related to stand by generation, such as primary energy, maintenance and operation costs. A flexibility action consisting in reducing Air Conditioning load in a supermarket will have 
to consider as direct costs the control and monitoring equipment costs, and as indirect, the possible loss of revenues derived from the loss of customer comfort.

The direct costs are motivated by the need to implement new technology and systems to put into service the customer flexibility. These systems can be associated to a single or to several flexibility actions. For example, the cost of a thermal storage system has to be associated to flexibility actions that translate part of the load from "expensive" energy periods to "cheap" periods, and the cost will be reflected only in the corresponding price. On the other side, there are systems, such as control and monitoring, that will be used to implement almost any flexibility action and, therefore, the cost has to be shared by all of them. An example of these systems for Demand Response infrastructure is the internet-based PG\&E InterActll system used in Automated Critical Peak Pricing in California during 2006/07 experiences [11].

The methodology proposed in this paper to price the flexibility is based on identifying the direct and indirect costs associated to each flexible kWh. First, the direct cost is computed by identifying the systems needed to implement the specific type of flexibility, the amount of this cost that has to be recovered by the payment of the flexibility. This last parameter is determined by an estimation of the time this system is to be used by the different applications. The number of hours that any piece of flexibility is to be used along the year has to be estimated previously and that depends very much on the mechanisms (market, bilateral, tariff, etc.) to trade this flexibility.

After this time of use for every flexibility package is determined, the cost share of the involved systems can be determined and so the total direct cost imputable to a flexibility package. A typical result of this estimation is shown in tables 3 and 4 , where the use of the utilization of any system is assigned to the different flexible processes.

Table 3.

Extra direct costs resulting from the flexibility

\section{Code Concept}

S1 Primary Energy Generation Cost

S2 Electricity Storage Cost

S3 Thermal Storage Cost

S4 Control Equipment Cost

S5 Monitoring and Measurement Equipment Cost

S6 Communication Equipment Cost 
Table 4.

Process cost matrix. Each column of this table represents the percentage of use of each direct cost concept by the different end uses according to the utilization due to their flexibility.

\begin{tabular}{|c|c|c|c|c|c|c|}
\hline End use & s1 & S2 & S3 & S4 & S5 & s6 \\
\hline HVAC & 5,9 & - & 82,4 & 9,1 & 9,1 & $y$ \\
\hline Ventilation & 11,8 & - & - & 13,6 & 13,6 & 13,6 \\
\hline Lighting & 58,8 & - & - & 11,4 & 11,4 & 11 \\
\hline Electroni & & 95,7 & - & 56,8 & 56,8 & 56 \\
\hline Others & 23,5 & 4,3 & 17,6 & 9,1 & 9,1 & 9 \\
\hline
\end{tabular}

The impact of the flexibility in the service provided by the corresponding piece of electric energy has to be evaluated in order to asses on the indirect costs of the flexibility. An important part of this cost is motivated by higher personnel costs resulting from electricity consuming processes rescheduling although some other components may be important (loss of production, public image deterioration, and any other loss of revenue). According to that, and for the commercial sector, the developed tools help identifying the technical flexibility not allowing significant degradation of the service and assigning to each energy package the associated effects.

The new tool which has been developed by the authors in order to evaluate the economical parameters associated to the flexibility complements other previously developed for estimation of the available technical flexibility with the described methodology in the previous section and some results that are shown in the next section. A cost data input screen for this tool is shown in Figure 3, where the detail of the considered information can be observed. Standard data menus with current commercial data about prices and characteristics of existing technologies are embedded in the tool in order to ease the use of it. 


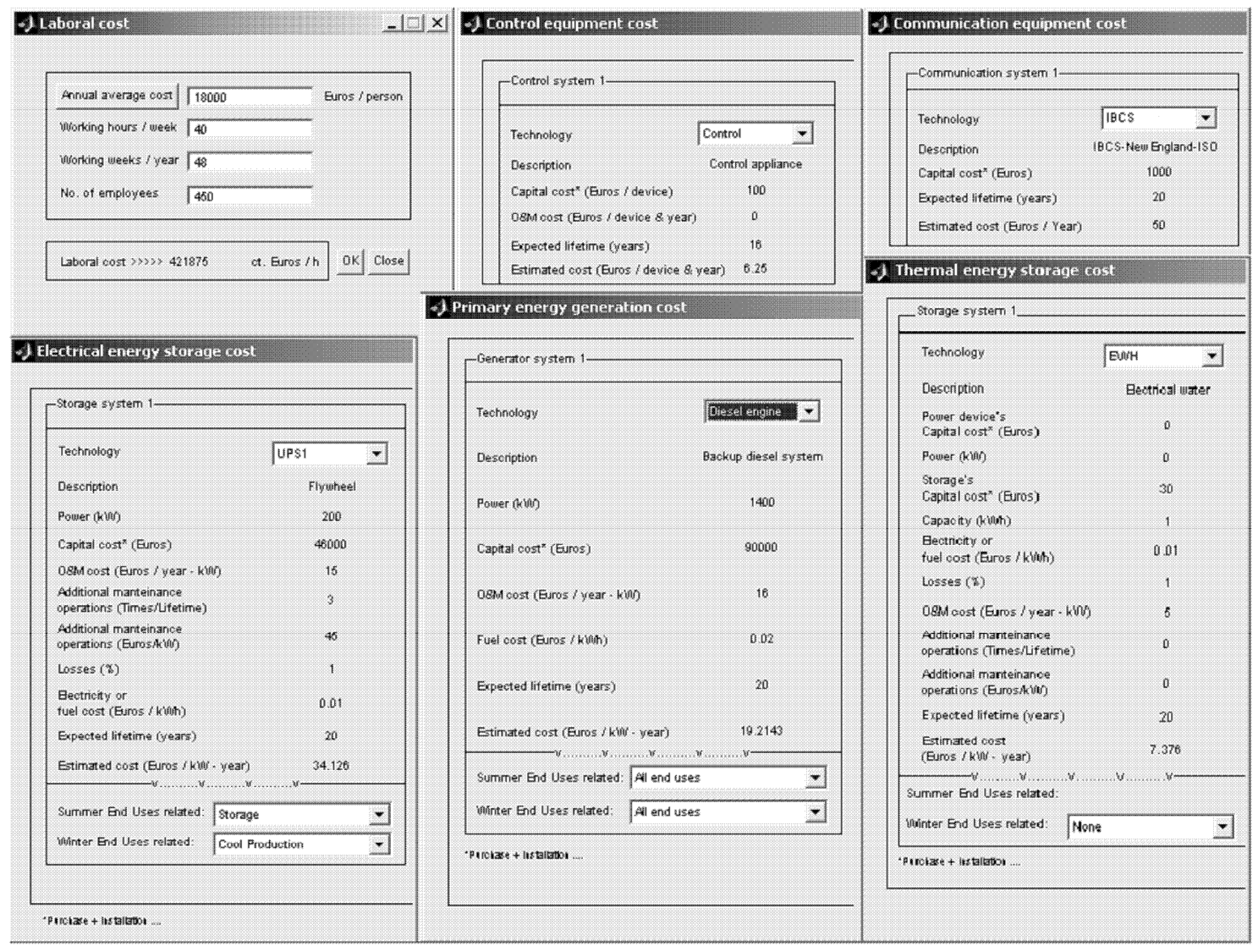

Figure 3. Input data screen in the developed tool

\section{Application}

The following results have been obtained by applying the methodology exposed above to the segment coded 99.01-04 "Large offices - Northern". The main characteristics for this segment are:

- Electricity consumption: $0.16<$ annual consumption $<1.25 \mathrm{GWh}$

- Gas consumption: annual consumption $<116 \mathrm{GWh}$

- Location: North of Europe

A real consumer from UK was selected as the typical customer to represent this segment, customer that is currently participating in the first experiment of the project EU-DEEP

\subsection{End uses identification}

Comprehensive information about the customer description, end uses or for example weather parameters has been gathered in order to describe and model it. Four relevant electricity consuming end uses have been identified as shown in Figure 4. 

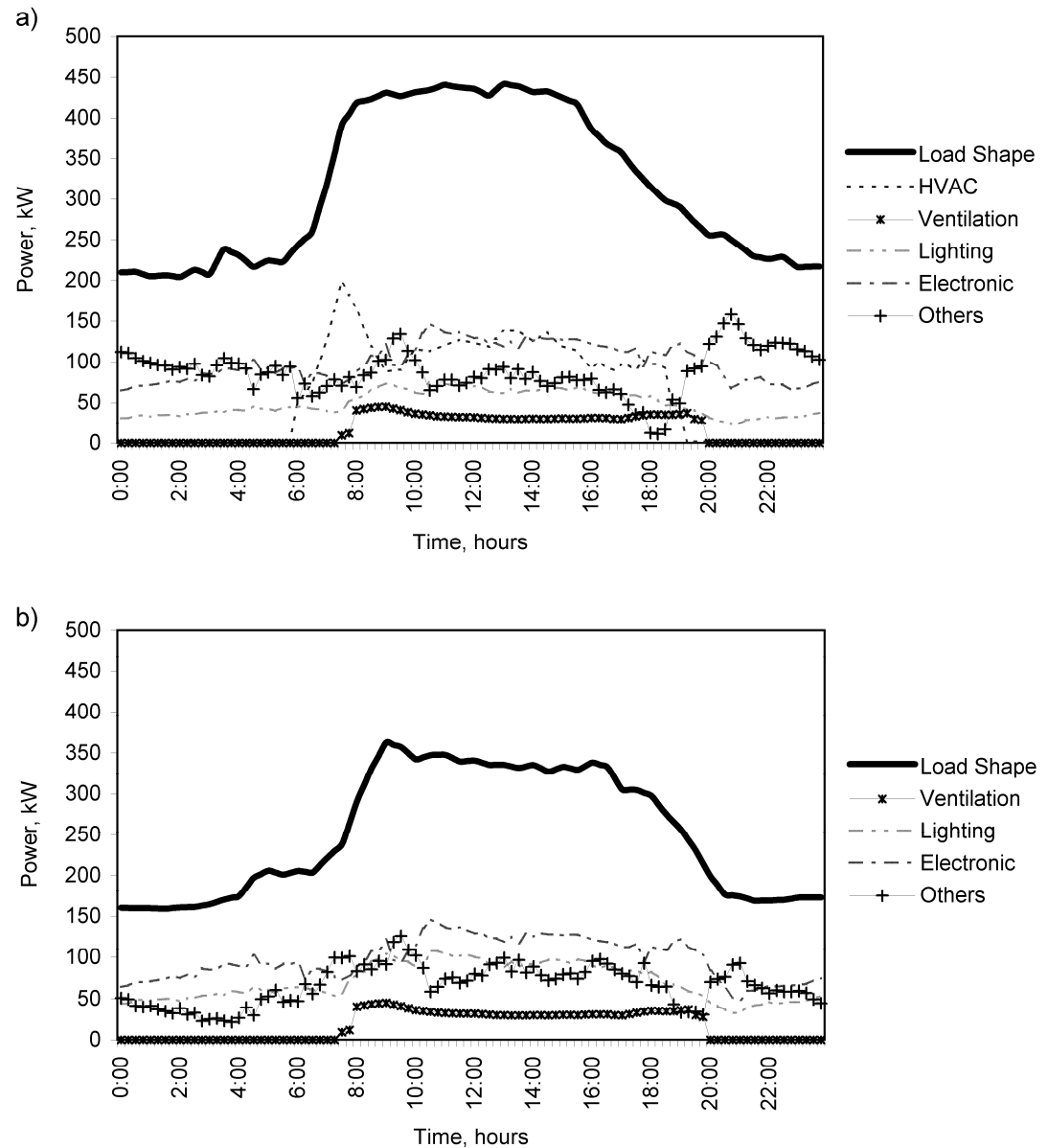

Figure 4. Typical load curves in (a) summer and (b) winter for large offices divided into end uses

Table 5 shows the consumptions for the different end uses of the segment for the typical customer in summer and winter.

Table 5:

Electricity consumption ratios for the segment 99.01-04 "Large offices - Northern"

\section{Summer Winter}

\begin{tabular}{ccc} 
& & \\
\hline HVAC & $20 \%$ & $0 \%$ \\
\hdashline Ventilation & $5 \%$ & $7 \%$ \\
\hline Lighting & $16 \%$ & $28 \%$ \\
\hline Electronic & $31 \%$ & $39 \%$ \\
\hline Others & $28 \%$ & $26 \%$
\end{tabular}


The end use "electronics" has the largest consumption in both summer and winter, since computers and other electronic devices are connected during the whole day. HVAC devices are partially controlled and disconnected during the night.

The peak of demand is higher in summer than in winter since the space heaters are working by using a different source than electricity (usually natural gas). As it is shown below in table 6 , HVAC and electronics are the two end uses whose power demand has the largest weight in the total demand on peak hours (at 12:00) in summer.

Table 6:

Contribution of each end use to the to the peak demand at noon for the segment 99.01-04

"Large offices - Northern"

\begin{tabular}{ccc} 
& Summer & Winter \\
\hline HVAC & $28 \%$ & $0 \%$ \\
\hline Ventilation & $7 \%$ & $9 \%$ \\
\hline Lighting & $16 \%$ & $29 \%$ \\
\hline Electronic & $30 \%$ & $38 \%$ \\
\hline Others & $19 \%$ & $23 \%$
\end{tabular}

\subsection{Flexibility and demand response evaluation}

The highest potential in demand response has been identified in HVAC and ventilation. Figure 5 shows the effect of applying different flexibility options in the total load curve of the consumer. In summer, the end use HVAC could be modified by allowing the temperature to be increased up to $2^{\circ} \mathrm{C}$ during a period of 2 hours a day. By doing that, a maximum reduction of about $120 \mathrm{~kW}$ (27\% of reduction in the total peak of power) may be obtained. Additionally, a decrement in ventilation could be got by decreasing the speed of the fan. If it is done while the HVAC payback period is taking place, a lower recovering peak is obtained. 


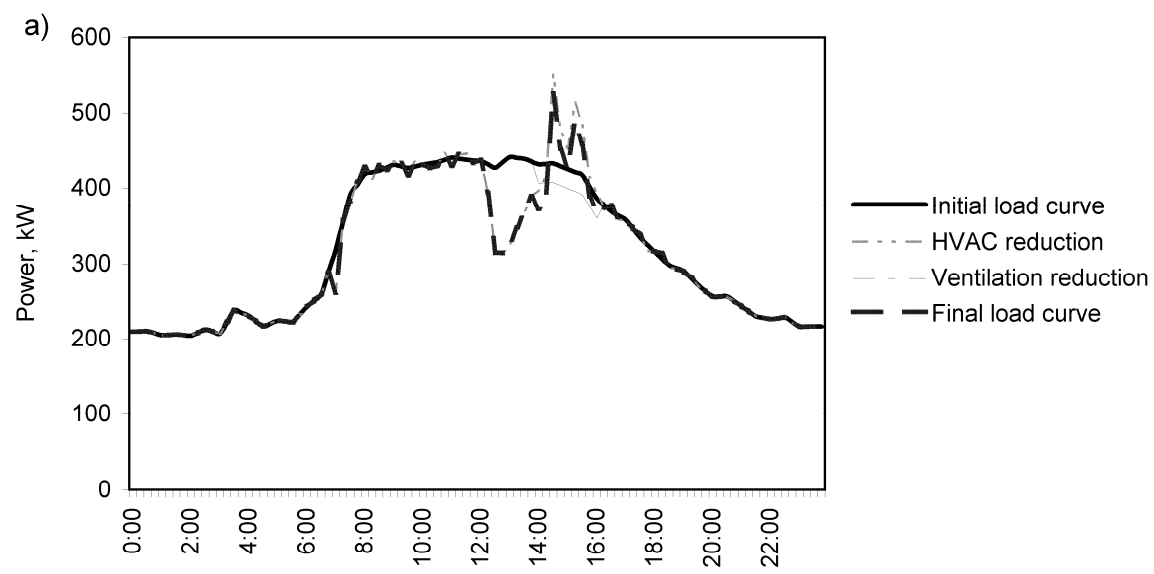

Time, hours

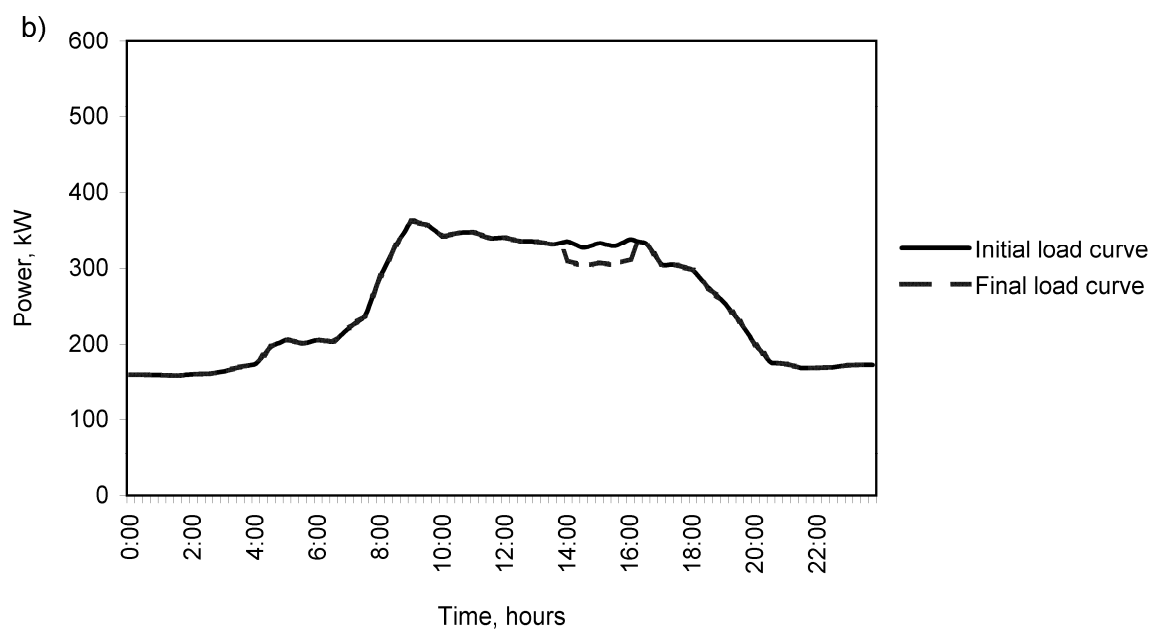

Figure 5. Flexibility associated to HVAC and ventilation for large offices in (a) summer and (b) winter

In winter, only the ventilation could be used as a demand response option, and a reduction of $25 \mathrm{~kW}$ ( $8 \%$ in the total peak of power) may be reached.

\subsection{Economic assessment}

Figure 6 shows the prices associated to the demand packages that could be reduced on peak hours (in this case, at 14:00 h). 

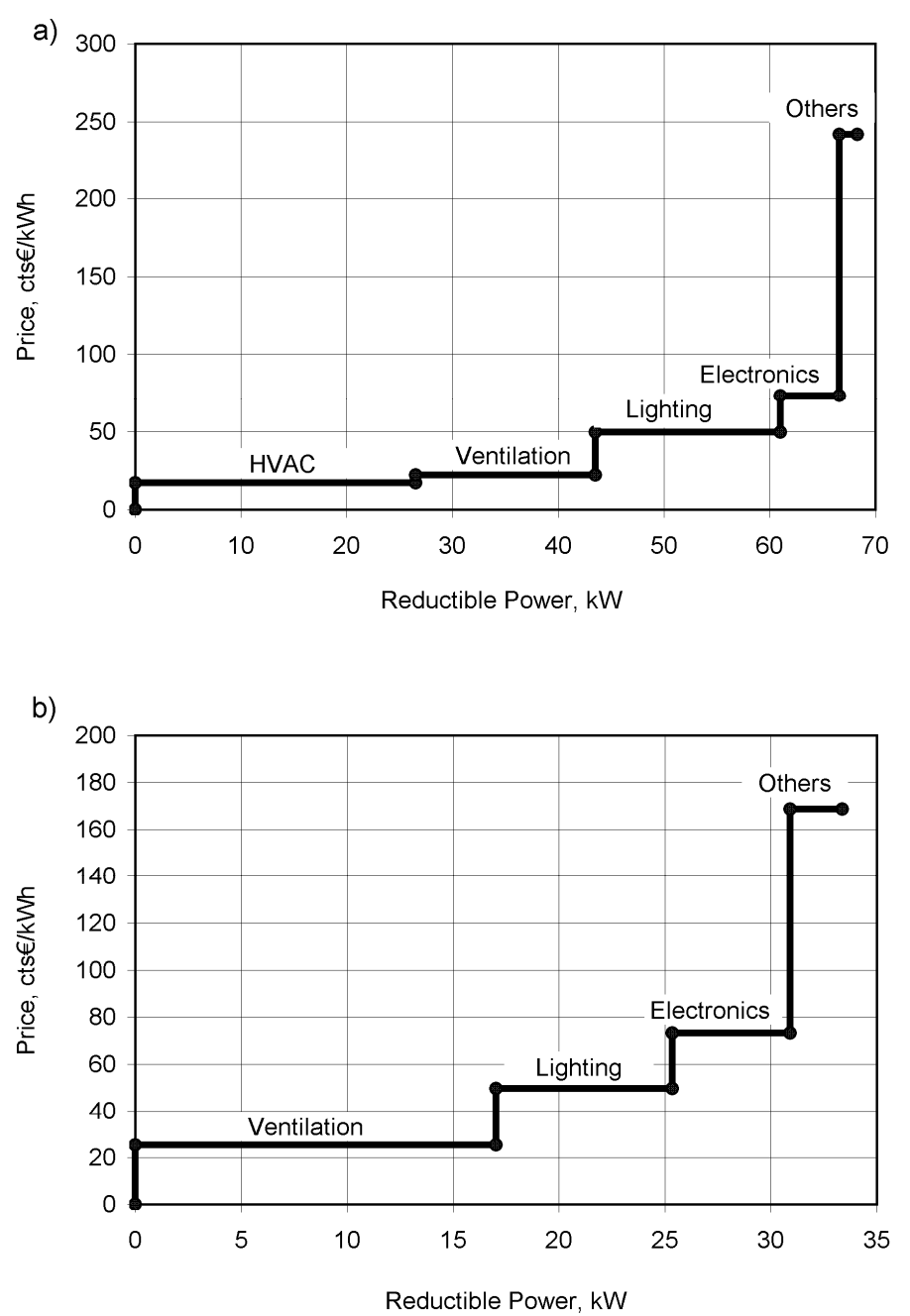

Figure 6. Offers for the different end uses in large offices at 14:00 $\mathrm{h}$ in (a) summer and (b) winter

The cheapest demand package to be reduced is HVAC, which may be decreased in about $27 \mathrm{~kW}$ if the consumer is paid in, at least, $27 \mathrm{cts} € / \mathrm{kWh}$ reduced. Ventilation, lighting and electronics are, in this order, the following processes to be reduced. A total amount of $73 \mathrm{~kW}$ could be decreased if the consumer was paid in $66 \mathrm{cts} € / \mathrm{kWh}$ reduced. The most expensive process is the one called "others", which consists on small and difficult to control processes.

It is similar in winter, where the ventilation could be reduced in about $17 \mathrm{~kW}$ if the customer was paid in $25 \mathrm{cts} € / \mathrm{kWh}$ reduced. 


\section{Conclusions}

This paper describes a two steps methodology that would allow a customer to participate in electricity markets or negotiate bilateral trading mechanisms with the agents capable to use the customer price responsive capability to enhance the electric energy systems behaviour.

The first step is designed to identify the technical potential of every single customer; i.e. the amount of power and energy reduction that is able to implement any hour (or for shorter periods) along any considered period (week, year, etc.). Side effects of the flexibility implementation can also be identified with this tool, such as service degradation, recovery energy required, etcetera and, consequently, the associated limitations to the use of each flexibility package (number times this flexibility can be used along a day/week, required notification times) as well as other parameters that have to be used to asses in the cost the implementation of any type of flexibility produces in the customer.

The second step allows the completion of the technical flexibility with the associated costs, direct and indirect, originated by the use of the each flexibility the customer may implement. The information provided with this tool provides the customer with all the necessary information to trade with his flexibility.

A real example of the application of this tool has been described, where the results of the tool were supplied to the customer and, after some iteration, full agreement was achieved in the flexibility figures.

\section{Acknowledgments}

This research work has been possible with the support of the European Commission through EU-DEEP project, and through the support of the Spanish Government (Ministerio de Educación y Ciencia) under Reasearch Project ENE2007-67771-C02-01\&02/CON and Red Eléctrica de España, S.A. (the Spanish System Operator) through the collaboration with the International Energy Agency project on DSM. 


\section{References}

[1] Kirschen, D.S.: "Demand-side view of electricity markets", IEEE Trans. Power Systems, May 2003, Vol. 18 , pp. $520-527$

[2] Rassanti, S., Smith, V. \& Wilson, B.: "Controlling Market Power and Price Spikes in Electricity Networks: Demand-Side Bidding", Interdisciplinary Centre for Economic Science, George Mason University, July 2001

[3] Pérez Arriaga, J.L.: "Libro blanco sobre la reforma del marco regulatorio de la generación eléctrica en España", Ministerio de Industria, Turismo y Comercio, Madrid June 2005

[4] Heffner, G.C.: "Configuring Loads as a Resource for Competitive Electricity Markets Review of Demand Response Programs in U.S. and Around the World", Laurence Berkeley National Laboratory, Nov. 2002

[5] Levy Associates: "A VISION OF DEMAND RESPONSE - 2015" California Energy Commission PIER interim report, California, January 2006

[6] Ruff, L: "Economic Principles of Demand Response in Electricity," prepared for Edison Electric Institute, October 2002

[7] Encinas, N., Alfonso, D., Álvarez, C., Pérez-Navarro, A. and García-Franco, F.: "Energy Market Segmentation for DER Implementation Purposes", IET Generation, Transmission and Distribution, March 2007, vol 1, issue 2,

[8] Afonso, D., Pérez-Navarro, A., Encina, N., Álvarez, C., Rodríguez, J. and Alcázar, M.: "A methodology for ranking of customer segments by their suitability for Distributed Energy Resources applications", Elsevier Energy Conversion and Management 48 (2007), pp. 16151623

[9] http://www.demandresponseresources.com accessed December 2007

[10] Álvarez, C., Gabaldón, A., and Molina, A.: "Assessment and Simulation of the Responsive Demand Potential in End-User Facilities: Application to a University Customer", IEEE Trans. Power Syst., 2004, 19, (2), pp. 1223-1231

[11] Lawrence Berkeley National Laboratory (Demand Response Research Center). "Automated Critical Peak Pricing Field Test: 2006 Program description and results", PIER Interim Project, 2007, CEC-500-03-026. Available on line http://eetd.Ibl.gov 